\title{
Infectious Disease Pathway
}

National Cancer Institute

\section{Source}

National Cancer Institute. Infectious Disease Pathway. NCI Thesaurus. Code C39738.

A sequence of biological or biochemical events that are the result of contracting an infection. 